\title{
Survival probability loss from percutaneous coronary intervention compared with coronary artery bypass grafting across age groups
}

\author{
Umberto Benedetto, MD, PhD, ${ }^{\mathrm{a}}$ Mohamed Amrani, MD, PhD, ${ }^{\mathrm{a}}$ Toufan Bahrami, MD, \\ Jullien Gaer, FRCS(C-Th), ${ }^{a}$ Fabio De Robertis, MD, ${ }^{a}$ Robert D. Smith, MD, ${ }^{b}$ and \\ Shahzad G. Raja, FRCS(C-Th), ${ }^{a}$ on behalf of the Harefield Cardiac Outcomes Research Group
}

\begin{abstract}
Background: Whether the survival benefit from coronary artery bypass grafting (CABG), compared with percutaneous coronary intervention (PCI), for multivessel disease extends to the older segment of the population remains unclear. We aimed to investigate whether the effect on survival of PCI compared with CABG is related to the age of the patient.
\end{abstract}

\begin{abstract}
Methods: Propensity score-matching analysis was conducted on 6723 patients $(\mathrm{PCI}=1097, \mathrm{CABG}=5626)$ with multivessel coronary artery disease. In the PCI group, drug-eluting stents were used in $917(83.5 \%)$ patients; bare metal stents were used in only 180 patients $(16.5 \%)$. Nonparametric, bootstrap, point-wise confidence limits were obtained for PCI:CABG odds and hazard ratios for early (within 12 months) and late hazard phase (beyond 12 months) for a variety of age groups.
\end{abstract}
Results: After a mean follow-up time of $5.5 \pm 3.2$ years, a total of 301 deaths were recorded in the matched sample (208 in the PCI group and 93 in the CABG group). Overall survival was $95 \% \pm 0.6 \%$ versus $95 \%$ $\pm 0.6 \%$ at 1 year, $84 \% \pm 1.0 \%$ versus $92.4 \% \pm 0.8 \%$ at 5 years, and $75 \% \pm 1.6 \%$ versus $90 \% \pm 1.0 \%$ at 8 years, for the PCI and CABG groups, respectively (log rank $P<.001$ ). PCI did not confer any significant benefit compared with CABG during the early hazard phase (within 12 months), but the survival-probability loss from PCI compared with CABG during the late hazard phase was present across all age groups. The hazard ratio declined from 3.8 to 3.4 and was statistically significant (lower limit $>1$ across all ages, ranging from 1.5 to 2.4$)$.

Conclusions: Compared with PCI, CABG leads to a significant reduction in late-phase mortality across all age groups. (J Thorac Cardiovasc Surg 2015;149:479-84)

See related commentary on pages 485-6.

Supplemental material is available online.

The optimal treatment approach for patients with multivessel coronary artery disease (CAD) remains controversial. ${ }^{1}$ Recent, large observational studies ${ }^{2-4}$ show that patients with multivessel CAD have a long-term survival advantage with coronary artery bypass grafting (CABG) compared

\footnotetext{
From the Departments of Cardiac Surgery ${ }^{\mathrm{a}}$ and Cardiology, ${ }^{\mathrm{b}}$ Harefield Hospital, London, United Kingdom.

Disclosures: Authors have nothing to disclose with regard to commercial support.

Received for publication June 1, 2014; revisions received Sept 21, 2014; accepted for publication Oct 4, 2014; available ahead of print Nov 6, 2014.

Address for reprints: Umberto Benedetto, MD, PhD, Department of Cardiac Surgery,

Harefield Hospital, London, UB9 6JH, United Kingdom (E-mail: umberto.

benedetto@hotmail.com).

$0022-5223 / \$ 36.00$

Copyright (c) 2015 by The American Association for Thoracic Surgery

http://dx.doi.org/10.1016/j.jtcvs.2014.10.032
}

with percutaneous coronary intervention (PCI). Several contemporary trials have reported similar mortality rates with these 2 treatment techniques ${ }^{5-7}$; however, all of these trials were underpowered to detect a difference in all-cause mortality. A recent meta-analysis ${ }^{8}$ that did not have the power limitation of those trials found that in patients with multivessel CAD, CABG leads to an unequivocal reduction in long-term mortality, compared with PCI, regardless of whether patients are diabetic. However, elderly patients were, in general, not included in the meta-analysis, or represented a small proportion of the trial population; therefore, whether these results apply to the older segment of the patient population needs to be determined.

Despite a lack of evidence that it is more effective, $\mathrm{PCI}$ is currently preferred for older patients, owing to the perceptions that CABG has higher operative mortality and that the potential survival advantage gained with $\mathrm{CABG}$ may be overshadowed in the elderly because of their limited life expectancy. ${ }^{9}$ The elderly represent one of the most rapidly expanding segments of the population in Western countries. ${ }^{10}$ Thus, determining the optimal strategy for revascularization in this complex context is an issue of 


$$
\begin{aligned}
& \text { Abbreviations and Acronyms } \\
& \begin{aligned}
\text { BMS } & =\text { bare metal stents } \\
\text { CABG } & =\text { coronary artery bypass grafting } \\
\text { CAD } & =\text { coronary artery disease } \\
\text { CI } & =\text { confidence interval } \\
\text { DES } & =\text { drug-eluting stents } \\
\text { HR } & =\text { hazard ratio } \\
\text { LAD } & =\text { left anterior descending } \\
\text { LMD } & =\text { left main disease } \\
\text { PCI } & =\text { percutaneous coronary intervention }
\end{aligned}
\end{aligned}
$$

public health concern. Therefore, we aimed to investigate whether the effect of PCI compared with CABG on survival is related to the patient's age.

\section{METHODS \\ Study Population}

The study was conducted in accordance with the principles of the Declaration of Helsinki. The local ethical committee approved the study, and the requirement for individual patient consent was waived. We retrospectively analyzed data collected prospectively from the institutional surgical and interventional database (PATS; Dendrite Clinical Systems, Ltd, Oxford, UK) from April 2001 to May 2013. The PATS database captures detailed information on a wide range of preoperative, intraoperative, and hospital postoperative variables (including complications and mortality) for all patients undergoing surgical or percutaneous myocardial revascularization in our institution. The database is maintained by a team of full-time clinical information analysts, who are responsible for continuous prospective data collection as part of a continuous audit process. Data collection is validated regularly.

Patients included in the final analysis met the following criteria: (1) they had multivessel CAD, defined as the presence of $\geq 2$ diseased vessels, including the left anterior descending (LAD) and/or the unprotected left main coronary artery, and (2) treatments included PCI or CABG (with at least 1 internal thoracic artery routinely used to graft the LAD). Exclusion criteria were that patients had (1) acute ST elevation myocardial infarction treated by primary PCI or salvage CABG, (2) rescue PCI, and/or (3) previous CABG (Figure E1). Overall, 6723 patients who underwent myocardial revascularization for multivessel $\mathrm{CAD}$ were included in the final analysis $(\mathrm{PCI}=1097, \mathrm{CABG}=5626)$. In the PCI group, drug-eluting stents (DES) were used in $917(83.5 \%)$ patients; bare metal stents (BMS) were used in only 180 patients $(16.5 \%)$.

\section{Pretreatment Variables and Study Endpoint}

The effect of PCI compared with CABG was adjusted for the following pretreatment variables: age, female gender, prior New York Heart Association functional class III-IV, prior myocardial infarction, prior PCI, diabetes mellitus, previous stroke, current smoking, chronic obstructive pulmonary disease, diseased vessels, left main disease (LMD), left ventricular ejection fraction $<50 \%$, serum creatinine concentration of $>200 \mu \mathrm{mol} / \mathrm{L}$, body mass index, and nonelective admission for index procedure.

The primary endpoint was all-cause death during follow-up (common closing date). All-cause death is the most robust and unbiased index because no adjudication is required; thus, inaccurate or biased documentation or clinical assessments are avoided. ${ }^{11}$ Information about death was obtained from the institutional database and the General Register Office for all patients.

\section{Statistical Analysis}

For baseline characteristics, variables are summarized as a mean for continuous variables, and as a proportion for categoric variables. Multiple imputation, using a bootstrapping-based expectation-maximization algorithm, was used to address missing data (Amelia II: A Program for Missing Data: http://www.jstatsoft.org/v45/i07/). The fraction of missing data ranged from $0 \%$ (number of vessels diseased) to $10.1 \%$ (body mass index). To control for measured potential confounders in the data set, a propensity score was generated for each patient from a multivariable logistic regression model based on pretreatment covariates as independent variables with treatment type (PCI vs CABG) as a binary dependent variable ${ }^{12}$ ( $\mathrm{R}$ package version 1.42: http://CRAN.R-project. org/package $=$ nonrandom). The resulting propensity score represented the probability that a patient underwent PCI rather than CABG (C-statistic: 0.78). Pairs of patients receiving $\mathrm{PCI}$ and $\mathrm{CABG}$ were derived using greedy $1: 1$ matching with a calliper of width 0.20 standard deviations of the logit of the propensity score. ${ }^{13}$ The quality of the match was assessed by comparing selected pretreatment variables in propensity score-matched patients using the standardized mean difference, by which an absolute standardized difference of $>10 \%$ is suggested to represent meaningful covariate imbalance.

Time-segmented semiparametric Cox proportional hazards regression analysis ${ }^{14}$ was conducted in the matched sample to assess the impact of revascularization strategies on mortality across age groups. The hazard function was used as a guide to determine approximate time points for the end of the early hazard phase and the beginning of the late phase (R package version 1.2.5: http://CRAN.R-project.org/package=muhaz). Second-order interaction between the treatment indicator and the patient's age (treatment*age) was forced in the 2 Cox models on early and late hazard phases.

Age linearity was assessed using a likelihood ratio test, including age as either a linear term or with a restricted spline fit (Table E1). The likelihood ratio test showed that the linear term for age alone was adequate for the early phase, but the restricted cubic spline form yielded a better fit for the late phase. A Schoenfeld residuals test ruled out violation of the proportional hazard assumption (Table E2 and Figure E2). The effect of treatment across age groups on early and late mortality hazard phases was obtained using nonparametric bootstrap covariance analysis for regression coefficients $(\mathrm{n}=1000$ repetitions) ( $\mathrm{R}$ package version 4.2-0: http://CRAN.R-project.org/package=rms). Subgroup analysis was performed according to the use of DES in the PCI group, the presence of LMD, and the number of diseased vessels. R version 3.1.0 (http://www. R-project.org) was used for statistical analysis. A $P$ value $<.05$ was considered significant for all tests.

\section{Propensity Score Matching}

Table 1 summarizes the distribution of pretreatment variables in the PCI group and in the unmatched and matched CABG group, with relative standardized mean difference and $P$ value. Before matching, patients treated with PCI were significantly different from those treated by CABG; overall, 7 of 14 pretreatment covariates showed a standardized mean difference $>10 \%$. In particular, CABG patients were more likely to have diabetes mellitus and more likely to present with triple-vessel disease and LMD. PS matching created a total of 1097 matching sets. After matching, all covariates were well balanced among the 2 groups.

\section{RESULTS}

\section{Overall Survival}

After a mean follow-up time of $5.5 \pm 3.2$ years, a total of 301 deaths were recorded in the matched sample (208 in the PCI group; 93 in the CABG group). Death occurred 
TABLE 1. Pretreatment variables in unmatched and matched PCI and CABG groups

\begin{tabular}{|c|c|c|c|c|c|c|c|c|c|c|}
\hline \multirow[b]{2}{*}{ Variable } & \multicolumn{2}{|c|}{$\begin{array}{c}\text { PCI } \\
\mathbf{n}=1097\end{array}$} & \multicolumn{2}{|c|}{$\begin{array}{c}\text { UM-CABG } \\
\mathbf{n}=\mathbf{5 6 2 6}\end{array}$} & \multirow[b]{2}{*}{ SMD } & \multirow[b]{2}{*}{$P$} & \multicolumn{2}{|c|}{$\begin{array}{l}\text { M-CABG } \\
\mathbf{n}=1097 \\
\end{array}$} & \multirow[b]{2}{*}{ SMD } & \multirow[b]{2}{*}{$P$} \\
\hline & $\mathbf{n}$ & $\%$ & $\mathbf{n}$ & $\%$ & & & $\mathbf{n}$ & $\%$ & & \\
\hline \multicolumn{11}{|l|}{ Age (y) } \\
\hline$<60.0$ & 357 & 32.5 & 1541 & 27.4 & 1.4 & .6 & 319 & 29.1 & 1.1 & .7 \\
\hline $60.0-70.0$ & 308 & 28.1 & 1947 & 34.6 & & & 363 & 33.1 & & \\
\hline $70.0-80.0$ & 322 & 29.4 & 1790 & 31.8 & & & 341 & 31.1 & & \\
\hline$>80$ & 110 & 10.0 & 348 & 6.2 & & & 74 & 6.7 & & \\
\hline \multicolumn{11}{|l|}{ Female } \\
\hline No & 835 & 76.1 & 4572 & 81.3 & 12.5 & $<.001$ & 823 & 75.0 & 2.5 & .5 \\
\hline Yes & 262 & 23.9 & 1054 & 18.7 & & & 274 & 25.0 & & \\
\hline \multicolumn{11}{|l|}{ MI } \\
\hline No & 795 & 72.5 & 3320 & 59.0 & 28.6 & $<.001$ & 790 & 72.0 & 1 & .8 \\
\hline Yes & 302 & 27.5 & 2306 & 41.0 & & & 307 & 28.0 & & \\
\hline \multicolumn{11}{|l|}{ Previous PCI } \\
\hline No & 973 & 88.7 & 4834 & 85.9 & 8.3 & .01 & 949 & 86.5 & 6.6 & .1 \\
\hline Yes & 124 & 11.3 & 792 & 14.1 & & & 148 & 13.5 & & \\
\hline \multicolumn{11}{|l|}{$\mathrm{DM}$} \\
\hline No & 858 & 78.2 & 4042 & 71.8 & 14.7 & $<.001$ & 860 & 78.4 & 0.4 & .9 \\
\hline Yes & 239 & 21.8 & 1584 & 28.2 & & & 237 & 21.6 & & \\
\hline \multicolumn{11}{|l|}{ LVEF $<0.50$} \\
\hline No & 862 & 78.6 & 4474 & 79.5 & 2.3 & .5 & 876 & 79.9 & 3.1 & .4 \\
\hline Yes & 235 & 21.4 & 1152 & 20.5 & & & 221 & 20.1 & & \\
\hline \multicolumn{11}{|l|}{ Nonelective } \\
\hline No & 792 & 72.2 & 3969 & 70.5 & 3.6 & .2 & 816 & 74.4 & 4.9 & .2 \\
\hline Yes & 305 & 27.8 & 1657 & 29.5 & & & 281 & 25.6 & & \\
\hline \multicolumn{11}{|l|}{ NYHA III-IV } \\
\hline No & 797 & 72.7 & 4024 & 71.5 & 2.5 & .4 & 792 & 72.2 & 1.02 & .8 \\
\hline Yes & 300 & 27.3 & 1602 & 28.5 & & & 305 & 27.8 & & \\
\hline \multicolumn{11}{|l|}{ Creatinine $\geq 200 \mu \mathrm{mol} / 1$} \\
\hline No & 1037 & 94.5 & 5492 & 97.6 & 15.9 & $<.001$ & 1047 & 95.4 & 4.1 & .3 \\
\hline Yes & 60 & 5.5 & 134 & 2.4 & & & 50 & 4.6 & & \\
\hline \multicolumn{11}{|l|}{ Smoke } \\
\hline No & 924 & 84.2 & 5030 & 89.4 & 15.3 & $<.001$ & 922 & 84.0 & 0.4 & .9 \\
\hline Yes & 173 & 15.8 & 596 & 10.6 & & & 175 & 16.0 & & \\
\hline \multicolumn{11}{|l|}{ Stroke } \\
\hline No & 1041 & 94.9 & 5372 & 95.5 & 5.1 & .3 & 1040 & 94.8 & 2.2 & .8 \\
\hline Yes & 56 & 5.1 & 254 & 4.5 & & & 57 & 5.2 & & \\
\hline BMI & & & & & & & & & & \\
\hline$<18.5$ & 21 & 1.9 & 28 & 0.5 & 1.5 & 6 & 9 & 0.8 & 1.6 & .7 \\
\hline $18.5-25.0$ & 289 & 26.3 & 1414 & 25.1 & & & 267 & 24.3 & & \\
\hline $25.0-30.0$ & 433 & 39.5 & 2572 & 45.7 & & & 503 & 45.9 & & \\
\hline$>30.0$ & 354 & 32.3 & 1612 & 28.7 & & & 318 & 29.0 & & \\
\hline Vessels disease & & & & & & & & & & \\
\hline LMD only & 56 & 5.1 & 72 & 1.3 & 80.9 & $<.001$ & 56 & 5.1 & 2.5 & .5 \\
\hline $\mathrm{LAD}+\mathrm{CX}$ & 368 & 35.5 & 811 & 14.4 & & & 365 & 33.2 & & \\
\hline $\mathrm{LAD}+\mathrm{RCA}$ & 325 & 29.6 & 522 & 9.3 & & & 320 & 29.1 & & \\
\hline $\mathrm{LAD}+\mathrm{CX}+\mathrm{RCA}$ & 348 & 31.7 & 4198 & 74.6 & & & 356 & 32.5 & & \\
\hline LMD & & & & & & & & & & \\
\hline No & 961 & 87.6 & 4007 & 71.2 & 41.3 & $<.001$ & 951 & 86.7 & 2.7 & .5 \\
\hline Yes & 136 & 12.4 & 1619 & 28.8 & & & 146 & 13.3 & & \\
\hline
\end{tabular}

PCI, Percutanous corornary intervention; $C A B G$, coronary artery bypass grafting; $U M$, unmatched; $S M D$, standardized mean difference; $M$, matched; $M I$, myocardial infarction; $D M$, diabetes mellitus; $L V E F$, left ventricular ejection fraction; NYHA, New York Heart Association; $B M I$, body mass index; $L M D$, left main disease; $L A D$, left anterior descending; $C X$, circumflex; $R C A$, right coronary artery. 


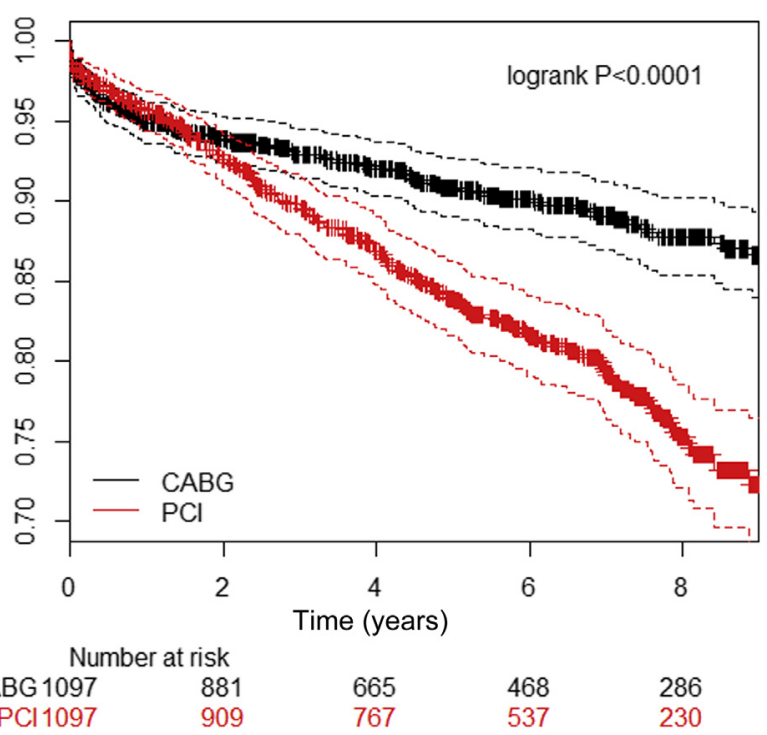

FIGURE 1. Nonparametric survival curves for PCI and CABG groups in the matched sample. $C A B G$, Coronary artery bypass grafting; $P C I$, percutaneous coronary intervention.

in 28 of $357 \mathrm{PCI}$ and 11 of $319 \mathrm{CABG}$ patients aged $<60$ years; in 44 of $308 \mathrm{PCI}$ and 29 of 363 CABG patients aged between 60 and 69 years; in 94 of 322 PCI and 36 of $341 \mathrm{CABG}$ patients aged between 70 and 79 years; and 42 of 110 PCI and 17 of 74 CABG patients aged $\geq 80$ years. Overall survival was $95 \% \pm 0.6 \%$ versus $95 \% \pm 0.6 \%$ at 1 year, $84 \% \pm 1.0 \%$ versus $92.4 \% \pm 0.8 \%$ at 5 years, and $75 \% \pm 1.6 \%$ versus $90 \%$ $\pm 1.0 \%$ at 8 years for the PCI and CABG groups, respectively (log rank $P<.001$; Figure 1$)$.

\section{Effect of Age on Survival Probability Loss From PCI Compared With CABG}

The instantaneous risk of death (the hazard function) was found to have 2 hazard phases for both the PCI and CABG groups. However, the first was a declining hazard phase from the time of operation (early hazard) throughout nearly the first 12 months in the CABG group (Figure 2), whereas in the PCI group, it was an increasing hazard phase from the time of index procedure throughout nearly the first 12 months. The early hazard phase accounted for 95 deaths $(\mathrm{PCI}=47$ and $\mathrm{CABG}=48)$. It then gave way to a steady hazard phase for both the PCI and $\mathrm{CABG}$ groups (late hazard) throughout the remainder of follow-up and accounted for 206 deaths (PCI $=161$ and $\mathrm{CABG}=45$ ). In the PCI group, the instantaneous risk presented a second steadily rising hazard phase beyond 5 years of follow-up.

\section{Early and Late Hazard Phases}

Bootstrap confidence limits analysis showed that PCI did not confer any significant benefit compared with

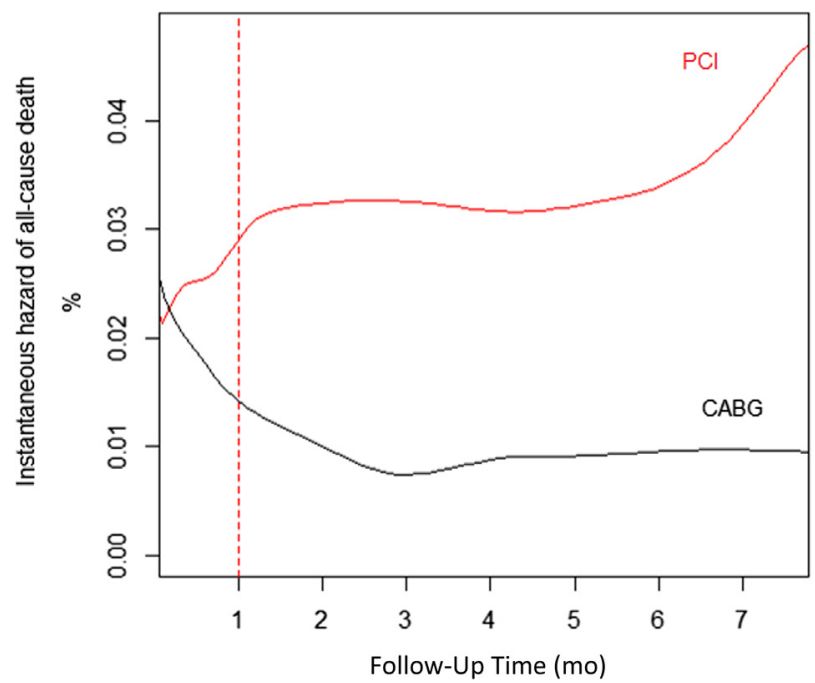

FIGURE 2. Hazard function for PCI and CABG groups in the matched sample. $P C I$, Percutaneous coronary intervention; $C A B G$, coronary artery bypass grafting.

CABG during the early hazard phase (within 12 months) across all age groups (Figure 3). The hazard ratio (HR) ranged from 1.1 to 1.2 and was not statistically significant (lower limit $<1$ across all ages). Bootstrap confidence limits analysis showed that the survival probability loss from PCI compared with CABG during the late hazard phase was present across all age groups (Figure 4). The HR declined from 3.8 to 3.4 and was statistically significant (lower limit $>1$ across all ages, ranging from 1.5 to 2.4). Subgroup analysis confirmed the superiority of CABG compared with PCI, across all age groups, for the late hazard phase when only DESPCI was included (Figure E3), in the case of 2-vessel disease (Figure E4), 3-vessel disease (Figure E5), and LMD (Figure E6).

\section{DISCUSSION}

The optimal revascularization strategy for patients with stable multivessel CAD remains controversial. ${ }^{1}$ The decision to recommend CABG or PCI ideally would be driven by a comparison of the short-term and long-term effect on outcomes, particularly mortality.

Recent evidence from randomized controlled trials strongly supports a survival advantage from CABG compared with PCI in patients with multivessel $\mathrm{CAD},{ }^{8}$ thus confirming previous findings from observational studies. ${ }^{2-4}$ However, whether the survival benefit from CABG compared with PCI extends to the older segment of the population remains unclear, as extrapolations from current trials among younger patients ${ }^{5-7}$ may not be accurate. Decision making in selecting the optimal strategy of revascularization according to the patient's age has traditionally been done without a compelling evidence 


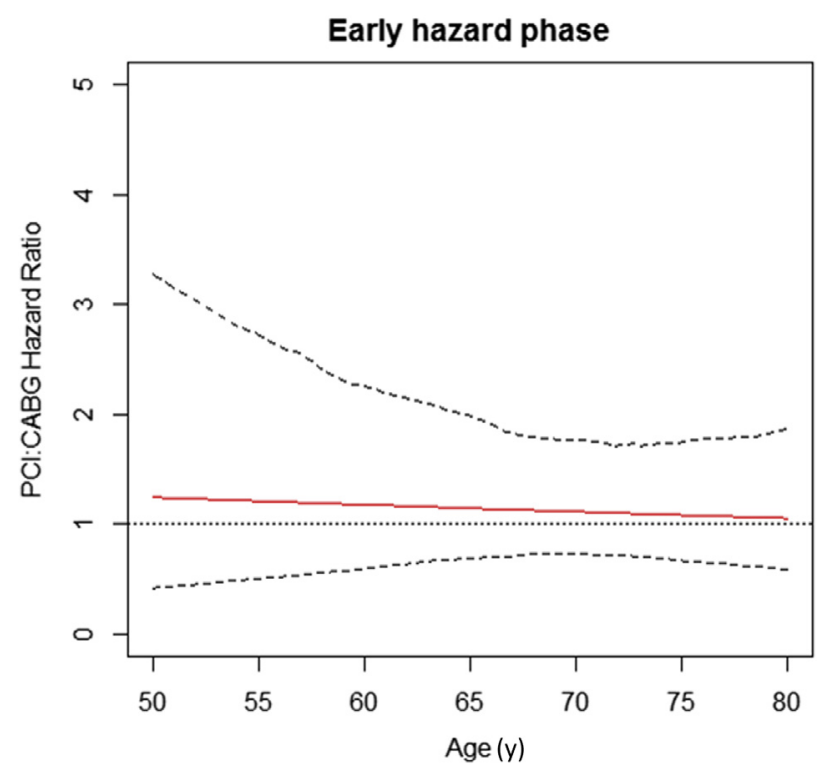

FIGURE 3. Nonparametric, bootstrap, point-wise $95 \%$ confidence limits (dotted lines) set for PCI versus CABG hazard ratios (red line) for a variety of ages during the early hazard phase (within 12 months). PCI, Percutaneous coronary intervention; $C A B G$, coronary artery bypass grafting.

base. PCI is often the preferred strategy in elderly patients, owing to the perceived increased early risk with CABG. ${ }^{9}$

Only a few observational studies have previously investigated the impact of age on late-survival probability loss from PCI compared with CABG, with discordant results. In the ASCERT (American College of Cardiology Foundation and The Society of Thoracic Surgeons Collaboration on the Comparative Effectiveness of Revascularization Strategies) study by Weintraub and colleagues, ${ }^{3}$ a lower mortality was reported for older $(>65$ years) patients with multivessel disease undergoing CABG compared with PCI (CABG/PCI risk ratio, 0.79; $95 \%$ confidence interval [CI], 0.76-0.82). An observational study by Hannan and colleagues, ${ }^{2}$ using data from New York's cardiac registries for patients with multivessel disease, found a nonsignificant trend toward a reduced risk for late death with CABG (adjusted CABG/PCI HR, 0.74; $95 \%$ CI, 0.55-1.00) for patients aged $\geq 80$ years. A New York study by $\mathrm{Wu}$ and colleagues ${ }^{4}$ found that $\mathrm{CABG}$ patients had overall higher 5-year survival rates than DES-PCI patients (CABG/DES HR for propensitymatched patients $0.71 ; 95 \%$ CI, 0.67-0.77). In addition, significantly lower risks of death were found for CABG for all age groups, although the level of significance was lower for older patients.

Recently, Hannan and colleagues ${ }^{9}$ found that older patients (age $\geq 75$ years) experienced similar mortality rates for CABG and PCI with DES (DES/CABG HR, 1.06; 95\% CI, 0.87-1.30) after a mean follow-up of 18 months. Palmerini and colleagues ${ }^{15}$ could not demonstrate a

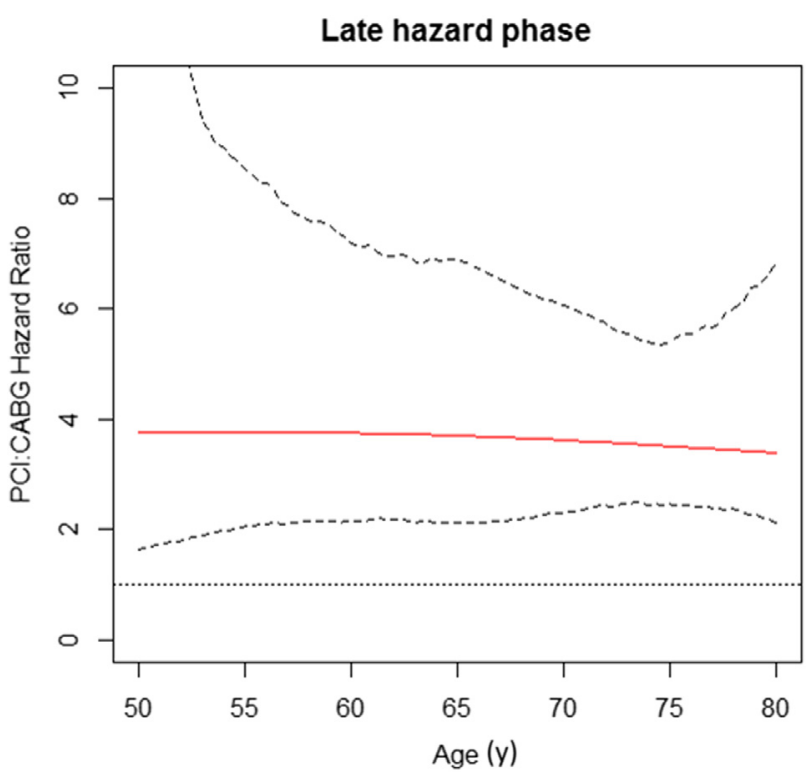

FIGURE 4. Nonparametric, bootstrap, point-wise $95 \%$ confidence limits (dotted lines) set for PCI versus CABG hazard ratios (red line) for a variety of ages during the late hazard phase (beyond 12 months). PCI, Percutaneous coronary intervention; $C A B G$, coronary artery bypass grafting.

difference in 2-year mortality between CABG-treated patients and those treated with DES for unprotected LMD. The conclusions of these last 2 studies were limited by the short follow-up duration.

A major limitation of previous investigations was that patients' ages were arbitrarily categorized. Categorization is associated with loss of both power and precision of estimates. Cut-off points are arbitrary and manipulable and are not consistent across studies. ${ }^{16}$ Furthermore, the point at which "young" becomes "old" is in continuous transition and may continue to advance as improved public health and lifestyle changes allow people to live longer.

To the best of our knowledge, this is the first study that focused on the impact of PCI compared with CABG on early- and late-stage survival across individual patient age in multivessel CAD. The present study showed that, contrary to the usual perception, PCI was not associated with a reduced early hazard across all age groups when patients were matched for all pretreatment variables. Moreover, the late-stage survival benefit from CABG extended to the older segment of the study population, and this finding was confirmed when CABG was compared with DES-PCI only.

Finally, our analysis supports the choice of using $\mathrm{CABG}$ rather than PCI regardless of the extent of CAD (including 2-vessel and 3-vessel disease). This conclusion is in line with a previous report on the superiority of $\mathrm{CABG}$, using the internal mammary artery grafted to the LAD, compared with DES-PCI in patients with isolated LAD disease. ${ }^{17}$ 
Finally, CABG appeared to be superior to PCI in patients with LMD, as suggested by a recent meta-analysis of randomized controlled trials. ${ }^{18}$

The present findings strongly support the hypothesis that age per se does not represent a contraindication for surgical revascularization in the presence of multivessel CAD. As with all observational studies, a caveat of our study is the selection bias introduced by not randomizing patients to the 2 treatments. We have tried to minimize this bias by propensity-matching patients using the large set of patient risk factors available in our CABG and PCI registries. After propensity matching, we found that patients receiving $\mathrm{CABG}$ and $\mathrm{PCI}$ were very similar with regard to the variables used in the matching process, as evidenced by acceptable low values of percent standardized differences. Nevertheless, a remaining threat to selection bias is unmeasured risk factors (eg, malignancy, dementia, poor mobility, frailty, severe concomitant illness) that are not contained in the registries, and this omission could have introduced a bias. Poor surgical candidates may have been more likely to have had PCI, whereas reasonable surgical candidates may have been more likely to be treated with CABG. Finally, given the relatively small sample size, subgroup analysis was not conclusive; studies with larger sample sizes and longer follow-up periods are needed to confirm these findings.

\section{CONCLUSIONS}

In patients with multivessel CAD, CABG does not increase operative mortality with increasing age and does lead to a significant reduction in long-term all-cause mortality across all age groups. Given these meaningful benefits, CABG should be the preferred revascularization method for most patients with multivessel CAD, regardless of the age of the patient.

\section{References}

1. Deb S, Wijeysundera HC, Ko DT, Tsubota H, Hill S, Fremes SE. Coronary artery bypass graft surgery vs percutaneous interventions in coronary revascularization: a systematic review. JAMA. 2013;310:2086-95.

2. Hannan EL, Wu C, Walford G, Culliford AT, Gold JP, Smith CR, et al. Drug-eluting stents vs. coronary artery bypass grafting in multivessel coronary disease. N Engl J Med. 2008;358:331-41.

3. Weintraub WS, Grau-Sepulveda MV, Weiss JM, O’Brien SM, Peterson ED, Kolm P, et al. Comparative effectiveness of revascularization strategies. N Engl J Med. 2012;366:1467-76.
4. Wu C, Camacho FT, Zhao S, Wechsler AS, Culliford AT, Lahey SJ, et al. Long-term mortality of coronary artery bypass graft surgery and stenting with drug-eluting stents. Ann Thorac Surg. 2013;95:1297-305.

5. Serruys PW, Ong AT, van Herwerden LA, Sousa JE, Jatene A, Bonnier JJ, et al. Five-year outcomes after coronary stenting versus bypass surgery for the treatment of multivessel disease: the final analysis of the Arterial Revascularization Therapies Study (ARTS) randomized trial. J Am Coll Cardiol. 2005;46:575-81.

6. Mohr FW, Morice MC, Kappetein AP, Feldman TE, Ståhle E, Colombo A, et al. Coronary artery bypass graft surgery versus percutaneous coronary intervention in patients with three-vessel disease and left main coronary disease: 5-year follow-up of the randomised, clinical SYNTAX trial. Lancet. 2013;381: 629-38.

7. Magnuson EA, Farkouh ME, Fuster V, Wang K, Vilain K, Li H, et al. Cost-effectiveness of percutaneous coronary intervention with drug eluting stents versus bypass surgery for patients with diabetes mellitus and multivessel coronary artery disease: results from the FREEDOM trial. Circulation. 2013; 127:820-31.

8. Sipahi I, Akay MH, Dagdelen S, Blitz A, Alhan C. Coronary artery bypass grafting vs percutaneous coronary intervention and long-term mortality and morbidity in multivessel disease: meta-analysis of randomized clinical trials of the arterial grafting and stenting era. JAMA Intern Med. 2014;174: 223-30.

9. Hannan EL, Zhong Y, Berger PB, Walford G, Curtis JP, Wu C, et al. Comparison of intermediate-term outcomes of coronary artery bypass grafting versus drug-eluting stents for patients $\geq 75$ years of age. Am J Cardiol. 2014; 113:803-8.

10. Raja SG. Myocardial revascularization for the elderly: current options, role of off-pump coronary artery bypass grafting and outcomes. Curr Cardiol Rev. 2012;8:26-36.

11. Holmes DR Jr, Kip KE, Kelsey SF, Detre KM, Rosen AD. Cause of death analysis in the NHLBI PTCA Registry: results and considerations for evaluating long-term survival after coronary interventions. J Am Coll Cardiol. 1997;30: 881-7.

12. Blackstone EH. Comparing apples and oranges. J Thorac Cardiovasc Surg. 2002; 123:8-15.

13. Austin PC. The performance of different propensity score methods for estimating marginal hazard ratios. Stat Med. 2013;32:2837-49.

14. Myers WO, Blackstone EH, Davis K, Foster ED, Kaiser GC. CASS Registry long term surgical survival. Coronary Artery Surgery Study. J Am Coll Cardiol. 1999; 33:488-98.

15. Palmerini T, Barlocco F, Santarelli A, Bacchi-Reggiani L, Savini C, Baldini E, et al. A comparison between coronary artery bypass grafting surgery and drug eluting stent for the treatment of unprotected left main coronary artery disease in elderly patients (aged $>$ or $=75$ years). Eur Heart J. 2007;28: 2714-9.

16. MacCallum RC, Zhang S, Preacher KJ, Rucker DD. On the practice of dichotomization of quantitative variables. Psychol Meth. 2002;7: 19-40.

17. Benedetto U, Raja SG, Soliman RF, Albanese A, Jothidasan A, Ilsley CD, et al. Minimally invasive direct coronary artery bypass improves late survival compared with drug-eluting stents in isolated proximal left anterior descending artery disease: a 10-year follow-up, single-center, propensity score analysis. J Thorac Cardiovasc Surg. 2014;148:1316-22.

18. Benedetto U, Ng C, Smith R, Raja SG. Coronary artery bypass grafting is superior to first generation drug-eluting stents for unprotected left main coronary artery disease: an updated meta-analysis of 4 randomized controlled trials. J Thorac Cardiovasc Surg. 2014;148:2430-2. 


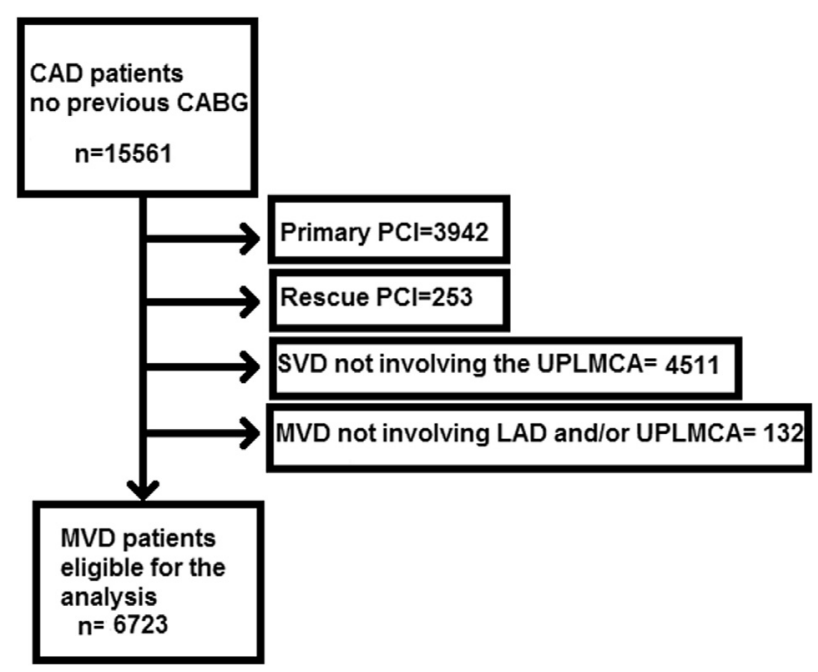

FIGURE E1. Patient selection flowchart. $C A D$, Coronary artery disease; $C A B G$, coronary artery bypass grafting; $P C I$, percutaneous coronary intervention; $S V D$, single-vessel disease; UPLMCA, unprotected left main coronary artery; $M V D$, multivessel disease; $L A D$, left anterior descending.
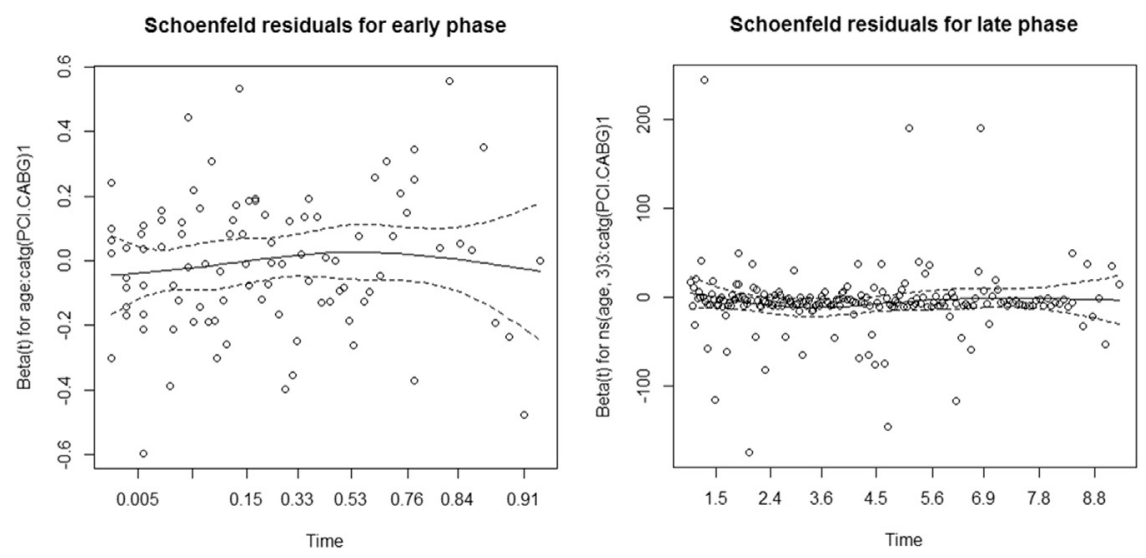

FIGURE E2. Schoenfeld residuals plot for Cox models for the early (left) and late (right) hazard phase. Catg, Category; PCI, percutaneous coronary intervention; $C A B G$, coronary artery bypass grafting; $n s$, nonsignificant. 
Late hazard phase - DES only

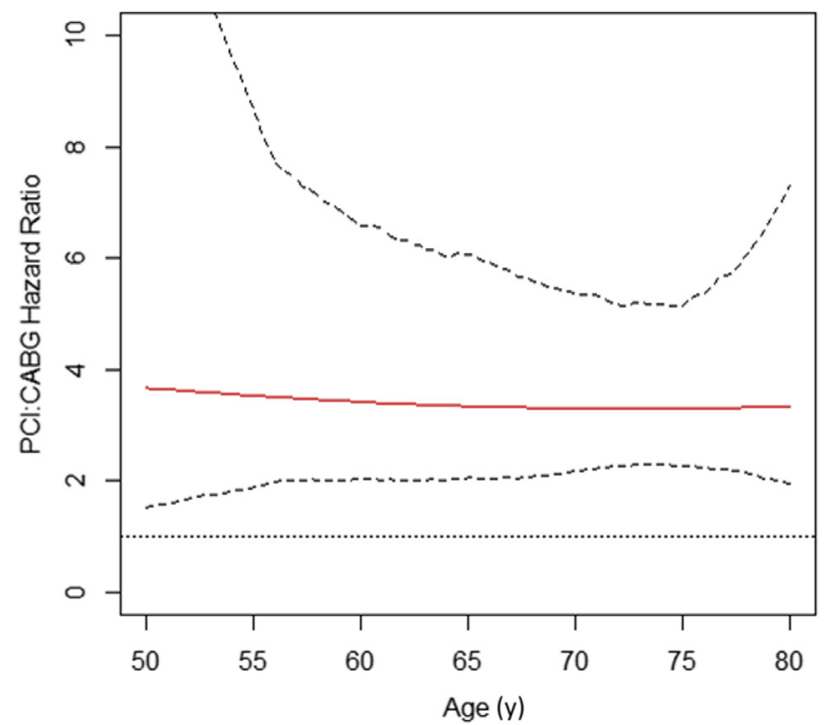

FIGURE E3. Nonparametric bootstrap point-wise $95 \%$ confidence limits (dotted lines) set for PCI versus CABG hazard ratios (red line) for a variety of ages during the late hazard phase (beyond 12 months) in subgroup analysis including DES only. DES, Drug-eluting stents; $P C I$, percutaneous coronary intervention; $C A B G$, coronary artery bypass grafting.

Late hazard phase-2-vessel disease-No LMD

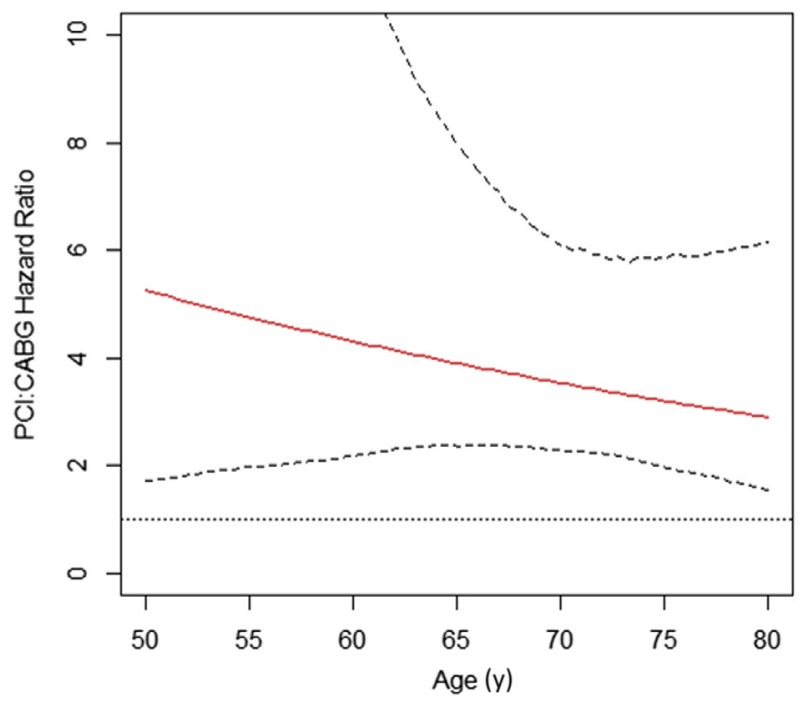

FIGURE E4. Nonparametric bootstrap point-wise $95 \%$ confidence limits (dotted lines) set for PCI versus CABG hazard ratios (red line) for a variety of ages during the late hazard phase (beyond 12 months) in subgroup analysis including 2-vessel disease only. $L M D$, Left main disease; $P C I$, percutaneous coronary intervention; $C A B G$, coronary artery bypass grafting.

\section{Late hazard phase - 3-vessel disease - No LMD}

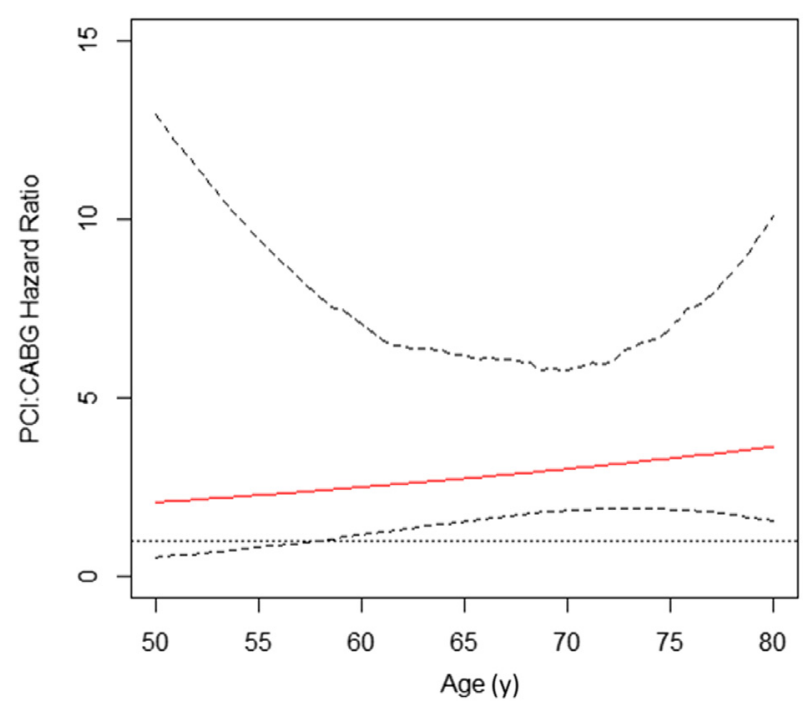

FIGURE E5. Nonparametric bootstrap point-wise $95 \%$ confidence limits (dotted lines) set for PCI versus CABG hazard ratios (red line) for a variety of ages during the late hazard phase (beyond 12 months) in subgroup analysis including 3-vessel disease only. $L M D$, Left main disease; $P C I$, percutaneous coronary intervention; $C A B G$, coronary artery bypass grafting.

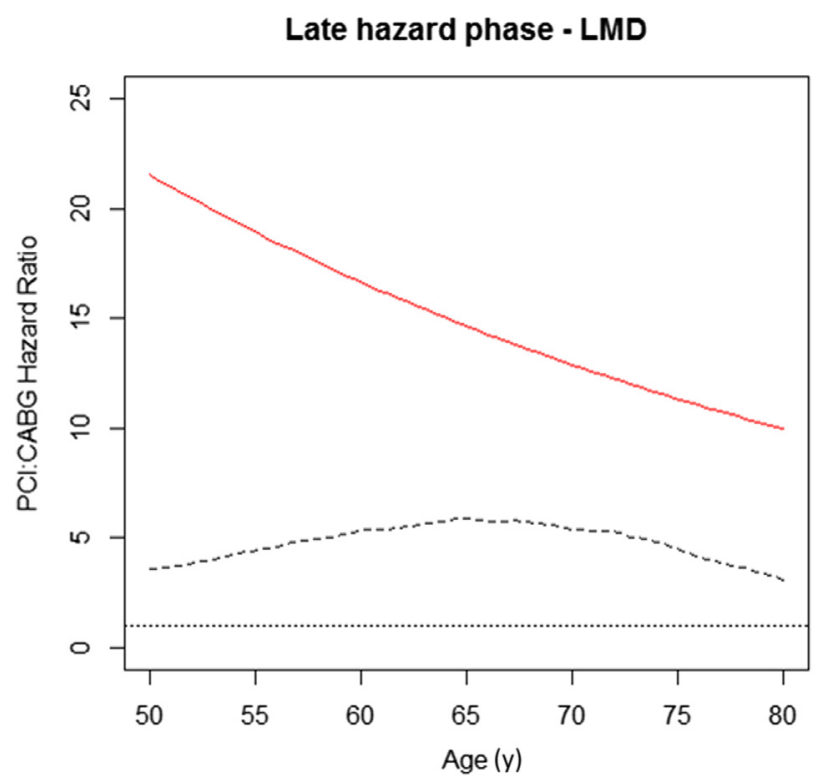

FIGURE E6. Nonparametric bootstrap point-wise $95 \%$ confidence limits (dotted lines) set for PCI versus CABG hazard ratios (red line) for a variety of ages during the late hazard phase (beyond 12 months) in subgroup analysis including LMD only. $L M D$, Left main disease; $P C I$, percutaneous coronary intervention; $C A B G$, coronary artery bypass grafting. 
TABLE E1. Analysis of deviance (early and late hazard phases, Cox models)

\begin{tabular}{|c|c|c|c|c|}
\hline Phase and models & Loglik & Chisq & $d f$ & $\boldsymbol{P}(>|\mathbf{C h i}|)$ \\
\hline \multicolumn{5}{|l|}{ Early phase } \\
\hline $\begin{array}{l}\text { Model 1: age * catg(PCI } \\
\text { vs CABG) }\end{array}$ & -452 & & & \\
\hline $\begin{array}{l}\text { Model 2: rcs(age, 2) * catg(PCI } \\
\quad \text { vs CABG) }\end{array}$ & -452 & 0.05 & 2 & .98 \\
\hline $\begin{array}{l}\text { Model 3: rcs(age, 3) * catg(PCI } \\
\quad \text { vs CABG) }\end{array}$ & -451 & 2.04 & 2 & .36 \\
\hline $\begin{array}{l}\text { Model 4: rcs(age, 4) * catg(PCI } \\
\quad \text { vs CABG) }\end{array}$ & -450 & 1.59 & 2 & .45 \\
\hline \multicolumn{5}{|l|}{ Late phase } \\
\hline Model 1: age catg(PCI vs CABG) & -1394 & & & \\
\hline $\begin{array}{l}\text { Model 2: } \operatorname{rcs}(\text { age }, 2) * \operatorname{catg}(\mathrm{PCI} \\
\quad \text { vs } \mathrm{CABG})\end{array}$ & -1392 & 3.41 & 2 & .18 \\
\hline $\begin{array}{l}\text { Model 3: } \sim \operatorname{rcs}(\text { age }, 3) * \operatorname{catg}(\mathrm{PCI} \\
\quad \text { vs } \mathrm{CABG})\end{array}$ & -1388 & 8.07 & 2 & .01 \\
\hline $\begin{array}{l}\text { Model 4: } \sim \operatorname{rcs}(\text { age }, 4) * \operatorname{catg}(\mathrm{PCI} \\
\quad \text { vs } \mathrm{CABG})\end{array}$ & -1387 & 1.69 & 2 & .43 \\
\hline
\end{tabular}

TABLE E2. Schoenfeld residuals test

\begin{tabular}{llll}
\hline & Rho & Chisq & $\boldsymbol{P}$ \\
\hline Early phase & & & \\
$\quad$ Age & -0.15 & 2.1 & .1 \\
catg(PCI vs CABG) & -0.05 & 0.3 & .5 \\
age:catg(PCI vs CABG) & 0.07 & 0.5 & .4 \\
Global & & 3.7 & .2 \\
Late phase & & & \\
ns(age, 3) & -0.003 & 0.002 & .9 \\
catg(PCI vs CABG) & -0.02 & 0.14 & .7 \\
ns(age, 3)3:catg(PCI vs CABG) & 0.02 & 0.07 & .7 \\
Global & & 5.4 & .6 \\
\hline
\end{tabular}

Chisq, Chi-square; catg, category; $P C I$, percutaneous coronary intervention; $C A B G$, coronary artery bypass grafting; $n s$, nonsignificant. 